\title{
Análisis de la demanda de antibióticos en farmacia comunitaria con receta privada, prescripción irregular y sin receta (automedicación): perfil de las farmacias y los farmacéuticos comunitarios participantes
}

\author{
Ana Molinero ${ }^{1,2,3,4}$, José A. Carbajal de Lara ${ }^{1,2,5,6}$, Fernando Cantalapiedra Fernández ${ }^{1,3,7,8}$, \\ Alejandro Eguilleor Villena ${ }^{1,7,9}$, Pedro Gutiérrez Ríos ${ }^{1,7,9,10}$
}

1. Grupo de trabajo de antibióticos de SEFAC. 2. Doctor en Farmacia 3. Profesor Asociado de la Universidad de Alcalá de Henares. 4. Farmacéutica comunitaria en Fuenlabrada. 5. Profesor Asociado de la Universidad de Castilla-La Mancha. 6. Farmacéutico comunitario en Albacete. 7. Licenciado en Farmacia. 8. Farmacéutico comunitario en Alcalá de Henares. 9. Farmacéutico comunitario en Madrid. 10. Profesor Asociado de la Universidad Complutense de Madrid

\section{PALABRAS CLAVE}

Antibacteriano, receta médica privada, prescripción irregular, automedicación, farmacéutico comunitario, farmacia comunitaria, atención farmacéutica

\section{ABREVIATURAS}

AEMPS: Agencia Española de Medicamentos y Productos Sanitarios ARNA: Antimicrobial Resistance and causes of Non-prudent use of Antibiotics in human medicine in the EU

ATC: Sistema de Clasificación

Anatómica, Terapéutica, Química

CA: comunidad autónoma

DE: desviación estándar

EPA-OD: Estudio post-comercialización transversal o de seguimiento retrospectivo

FC: farmacia comunitaria

CRD: cuaderno de recogida de datos

PRAN: Plan Nacional de Resistencia a los Antibióticos

SEFAC: Sociedad Española de Farmacia Familiar y Comunitaria

\section{RESUMEN}

Introducción: La resistencia a los antibióticos constituye uno de los mayores desafíos que afronta la medicina en la actualidad. Es una amenaza creciente para la salud pública que afecta a todos los países del mundo debido a que los nuevos mecanismos de resistencia se extienden a escala internacional.

Objetivos: Analizar el perfil profesional y el nivel de participación de los farmacéuticos comunitarios que realizan el estudio.

Describir el tipo de farmacia comunitaria, localización y nivel de participación.

Material y métodos: Estudio descriptivo, observacional, prospectivo, de corte transversal y multicéntrico realizado en farmacias comunitarias españolas durante cuatro semanas, una por cada estación. Se diseñó un cuaderno de recogida de datos que recogía las siguientes variables: tipo de farmacéutico y farmacia, variables sociodemográficas, antibiótico demandado, tipo y razón de la demanda, especialidad del médico prescriptor, tipo de tratamiento, conocimiento del proceso de uso del antibiótico, problemas relacionados con el medicamento y resultados negativos asociados a la medicación identificados, actuación e intervención del farmacéutico.

Se diseñó una plataforma web http://investigacionsefac.org/antibioticos/ para la recogida de datos.

Resultados: Registraron encuestas 341 farmacéuticos (57,3\% titulares y 35,6\% adjuntos) pertenecientes a 247 farmacias (65,6\% farmacias de barrio).

Conclusiones: Los farmacéuticos inscritos en este estudio son mayoritariamente adjuntos del sexo femenino y los más participativos titulares.

Las comunidades autónomas (CCAA) con mayor número de farmacias participantes han sido C. Valenciana, Cataluña y Madrid y las que más han registrado han sido las farmacias de la Comunidad Valenciana.

Las farmacias tipificadas como de barrio han sido mayoritarias y las que han registrado mayor número de casos.
Recibido: $14 / 1 / 2018$

Aceptado: 26/2/2018

Disponible online: $30-3-2018$
Financiación: el estudio ha sido financiado por la Agencia Española de Medicamentos y Productos Sanitarios (AEMPS), dentro del Plan Nacional de Resistencia a Antibióticos (PRAN).

Conflicto de intereses: ninguno.

Contribución a la autoria: los autores contribuyeron por iqual al diseño del estudio, desarrollo de la investigación análisis de los resultados, redacción del manuscrito y revisión del contenido final.

Cite este artículo como: Molinero A, Carbajal JA, Cantalapiedra F, Eguilleor A, Gutiérrez P. Análisis de la demanda de antibióticos en farmacia comunitaria con receta privada, prescripción irregular y sin receta (automedicación): perfil de las farmacias y los farmacéuticos comunitarios participantes. Farmacéuticos Comunitarios. 2018 Mar 30; 10(1):18-32. doi:10.5672/FC.2173-9218.(2018/Vol10).001.04

Correspondencia: Ana Molinero (anamolinero@sefac.org)

ISSN 1885-8619 OSEFAC (Sociedad Española de Farmacia Familiar y Comunitaria). Todos los derechos reservados. 


\section{KEYWORDS}

Anti-bacterial, private medical prescription, irregular prescription, self-medication, community pharmacist, community pharmacy,
Analysis of the demand for antibiotics in community pharmacy with private prescription, irregular prescription and without prescription (self-medication): profile of the participating pharmacies and community pharmacists

\section{ABSTRACT}

Background: Antibiotic resistance is one of the main challenges facing medicine today. It is a growing threat to public health that affects all countries in the world, since the new mechanisms of resistance spread on an international scale.

Objectives: To analyse the professional profile and level of participation of the CFs conducting the study.

To describe the type of pharmacy, location and level of participation.

Method: A prospective, cross-sectional, descriptive, observational multicentre study to be carried out in Spanish community pharmacies during four weeks - one in each season of the year. A case report form (CRF) is designed for collection of the following variables: type of pharmacist and pharmacy, sociodemographic data, antibiotic requested, type and reason for request, specialty of the prescribing physician, type of treatment, knowledge of the process of antibiotic use, drug-related problems and negative medication outcomes identified, and pharmacist behaviour and intervention.

A platform http://investigacionsefac.org/antibioticos/ is available for data compilation.

Results: A total of 341 community pharmacists (57.3\% owners and 35.6\% responsible pharmacist) in 247 community pharmacies (65.6\% local pharmacies) have registered in the study.

Conclusions: The pharmacists involved in this study are mostly female, responsible pharmacist and the most participative owners.

The Autonomous Regions with the largest number of participating pharmacies were Comunidad Valenciana and Cataluña, and the ones that registered the most were the pharmacies in Comunidad Valenciana.

The pharmacies classified as local pharmacies have been the majority and those that have registered the highest number of cases.

\section{Introducción}

La utilización de los antibióticos constituye uno de los mayores logros terapéuticos de la historia de la Medicina [1]: gracias a ellos podemos curar enfermedades que hasta principios del siglo pasado eran mortales. Antes de su descubrimiento el 90\% de los niños que padecían una meningitis bacteriana morían, y los que sobrevivian padecian discapacidades graves, sordera o retraso mental; las infecciones de garganta y otras infecciones como la tuberculosis, neumonía o tosferina, provocaban normalmente la muerte [2]. Además, han contribuido de forma significativa al progreso en campos tales como como los trasplantes de órganos sólidos y de progenitores hematopoyéticos, la supervivencia de prematuros e inmunodeprimidos, la cirugía de material protésico y los catéteres vasculares, donde las infecciones son especialmente prevalentes e importantes [3].

Sin embargo, son también el mayor problema médico de la historia [4], ya que desde el comienzo de su uso, la resistencia bacteriana a los antibióticos ha pasado de ser una amenaza a ser una realidad y constituye un problema mundial de salud pública [5-7].

El problema de la resistencia bacteriana podría derivar del mal uso/ abuso de los antibióticos. En la resolución WHA51.171 de la Asamblea Mundial de la Salud de 1998 [8] se instaba a los Estados Miembros a que adoptaran medidas encaminadas a promover la utilización apropiada y costo-eficaz de los antimicrobianos, a prohibir la distribución de antimicrobianos sin una prescripción o receta de un profesional de salud cualificado, a mejorar las prácticas para prevenir la propagación de la infección $\mathrm{y}$, de esa manera, la diseminación de microorganismos multirresistentes, a reforzar la legislación para impedir la fabricación, venta y distribución de fármacos antimicrobianos falsificados y la venta de antibióticos en el mercado paralelo, y a reducir la utilización de antimicrobianos en la cría de animales destinados al consumo. También se instaba a los países a que desarrollaran sistemas sostenibles para detectar resistencias bacterianas y para vigilar las cantidades y modalidades de uso de los antimicrobianos y los efectos de las medidas de control.

La sobreutilización de antibióticos es un factor determinante en el aumento de las infecciones resistentes a antibióticos. En Estados Unidos se estima que el 30\% de las prescripciones de antibióticos pueden haber sido innecesarias [9]. En España, según la Agencia Española de Medicamentos y Productos Sanitarios, entre el 40 y el 50\% de las prescripciones de antibióticos que se realizan en los servicios de atención primaria y hospitalaria son inadecuadas [10].

Desde 2014 el Instituto Holandés para la Investigación en Servicios de Salud (NIVEL) y la Universidad de Antwerpen (Amberes) participan en el proyecto ARNA (Antimicrobial Resistance and causes of Non-prudent use of Antibiotics in human medicine in the $E U$ ), financiado por la Comisión Europea [11]. Este proyecto nació para ayudar y contribuir a un uso más prudente de los antibióticos 
en medicina humana en Europa, focalizándose en el consumo de antibióticos sin prescripción médica y la automedicación. El objetivo principal de dicho proyecto es evaluar estas situaciones para fomentar políticas que conduzcan a un uso prudente de los antibióticos.

El proyecto ARNA se focaliza en los países que, tras el análisis de los resultados del Eurobarómetro realizado en 2013 sobre resistencia a antibióticos [12], mostraron un porcentaje más elevado de pacientes que decian haber consumido antibióticos en los últimos 12 meses. Estos países son: Rumanía (20\%), Grecia (16\%), Chipre (10\%), Hungría (8\%), España (8\%), Estonia $(7 \%)$, Italia (5\%). Media europea (5\%).

El mismo informe realizado tres años más tarde (2016) [13] muestra que, mientras que en la mayoría de los países europeos ha disminuido el número de consumidores de antibióticos durante el año anterior, en España ha aumentado hasta un 9\%, siendo el país europeo con mayor incremento. Sin embargo, en nuestro país el porcentaje de pacientes que dicen haber consumido antibióticos sin prescripción médica en 2016 ha bajado dos puntos porcentuales con respecto al Eurobarómetro de 2013, para situarse en el 6\%.

El farmacéutico comunitario constituye el primer eslabón de la cadena de asistencia sanitaria en muchas ocasiones, incluso algunas veces el único, $\mathrm{y}$ es el último agente de salud que ve el paciente antes de iniciar una terapia farmacológica [14]. Es el profesional experto en el medicamento, que puede asesorar al paciente en todo lo relacionado con el mismo (incluida la automedicación), puede recomendar un tratamiento farmacológico (que no necesite prescripción médica) o derivar al médico en los casos en que exista algún motivo de alarma o interferencia con otros problemas de salud o medicamentos y, además, puede desempeñar un papel clave en la educación al paciente en temas de salud [15].

Además, el farmacéutico comunitario tiene acceso a información relacionada con las prescripciones de receta privadas [16], que no pasan por el sistema sanitario público, así como a información relevante sobre la demanda de antibióticos sin receta o de prescripciones que no cumplen con todos los requisitos de la normativa oficial, aunque estén realizadas por profesionales médicos (informes de urgencia, prescripciones telefónicas, etc.). Obtener datos de estas situaciones puede ser de gran utilidad para implementar estrategias que conduzcan a un mejor uso de los antibióticos y a frenar las resistencias bacterianas.

Esto nos ha llevado a plantear un estudio sobre demanda de antibióticos en la farmacia, del cual solo describiremos aquí una parte del mismo, cuyo objetivo principal es cuantificar la proporción de la demanda de antibióticos por vía oral del grupo terapéutico ATC (Sistema de Clasificación Anatómica, Terapéutica, Química) J01 (antibacterianos para uso sistémico) con receta privada, prescripción irregular y sin prescripción médica en la farmacia comunitaria, con respecto a la demanda total de antibióticos por vía oral. Y los objetivos secundarios:

- Cuantificar la demanda de antibióticos del grupo J01 por vía oral con receta no financiada, prescripción irregular y sin prescripción durante el periodo de tiempo del estudio, así como el número de pacientes que los solicitan en las farmacias participantes.

- Aportar el dato del número de envases dispensados con receta privada de antibióticos por vía oral del grupo J01.

- Valorar la proporción de recetas privadas de antibióticos que cumplen la legislación vigente.

- Evaluar el porcentaje de prescripciones de antibióticos que no cumplen la normativa vigente (receta privada en formato anterior al del RD 1718/2010 [17], prescripción en informe de urgencias, prescripción telefónica).

- Analizar el perfil del médico prescriptor.

- Analizar el perfil de los antibióticos y sintomatología para la que se demandan.

- Cuantificar la automedicación y analizar las causas de por qué la población demanda antibióticos sin receta.

- Evaluar la intervención del farmacéutico.

- Realizar educación sanitaria sobre el uso correcto de antibióticos.

- Aportar el dato del número total de envases dispensados de an- tibióticos por vía oral del grupo terapéutico J01 demandados durante el periodo de tiempo del estudio.

El trabajo que aquí se presenta tiene como objetivos analizar el perfil profesional y el nivel de participación de los FC que realizan el estudio y el tipo, localización y nivel de participación de las farmacias.

\section{Material y métodos}

El proyecto promovido por SEFAC, Demanda de antibióticos en la farmacia comunitaria con el código SEF-ANT-2016-01, es un estudio descriptivo, observacional de corte transversal y multicéntrico realizado en farmacias comunitarias de todo el territorio nacional durante cuatro semanas, una de cada una de las estaciones del año: 21-27 de noviembre de 2016, 23-29 de enero de 2017, 3-9 de abril de 2017 y 19-25 de junio de 2017.

La metodología del estudio se basa en la utilizada en la tesis doctoral "Estudio de la demanda de antibióticos sin receta en la oficina de farmacia. Papel del farmacéutico en la automedicación" [18].

El estudio fue clasificado como EPA-OD por la Agencia Española de Medicamentos y Productos Sanitarios (AEMPS) y aprobado por el Comité Ético del Hospital de Fuenlabrada.

\section{Población del estudio}

\section{Farmacéuticos participantes}

Farmacéuticos comunitarios (titulares, adjuntos, sustitutos y regentes) ejercientes en farmacias comunitarias de todo el territorio nacional.

\section{Selección de los sujetos}

Demandantes de antibióticos pertenecientes al grupo terapéutico J01 de la guía ATC que acudan a las farmacias comunitarias incluidas en el estudio.

\section{Cálculo del tamaño muestral}

Basándonos en las ventas de antibióticos por vía oral del grupo terapéutico J01 de los tres últimos años, se estima un número aproximado de 1.200.000 demandas de antibióticos fuera del Sistema Nacional de Salud (SNS) en 4 semanas. 
Aplicando la fórmula:

$$
n=\frac{Z_{\alpha}^{2} N p q}{e^{2}(N-1)+Z_{\alpha}^{2} p q}
$$

con un nivel de confianza del 95\% y una precisión del 3\% y con una $\mathrm{p}$ de 0,5 , que maximiza el tamaño muestral al no conocer los porcentajes aproximados, se obtiene un tamaño muestral de 1.066 solicitudes de antibióticos.

\section{Población diana}

Sujetos que soliciten un antibiótico en la farmacia comunitaria.

\section{Criterios de inclusión}

Sujetos que soliciten un antibiótico del grupo terapéutico J01 para administración oral en la farmacia comunitaria.

\section{Criterios de exclusión}

- Sujetos con dificultades de comunicación, psicológicas o lingüísticas que, a criterio del investigador, no estén capacitados para responder a las preguntas del cuestionario.

- Sujetos que soliciten un antibiótico del grupo J01 para administración por vía diferente a la vía oral.

- Solicitantes de antibióticos con receta financiada por el SNS, mutualidades, mutuas de accidentes de trabajo y receta veterinaria.

\section{Procedimiento}

Se habilitó una plataforma informática (web) para recogida de datos: www.investigacionsefac.org/antibioticos/ y se ofertó la participación en el estudio a todos los socios de SEFAC, habilitándose el mes de octubre de 2016 para la inclusión de los participantes. Los farmacéuticos al inscribirse definían su sexo, edad, años de experiencia, puesto que desempeñaban en la farmacia e identificaban en qué tipo de farmacia trabajaban y dónde se encontraba ubicada dicha farmacia (anexo 1). La plataforma generaba un identificativo anónimo y exclusivo para cada farmacia.

Ante la demanda de un antibiótico del grupo terapéutico J01 por vía oral el farmacéutico iniciaba el protocolo de dispensación basado en Foro de Atención Farmacéutica en Farmacia Comunitaria [19], y, después de obtener el consentimiento del paciente, se realizaban las pre- guntas recogidas en un cuaderno de recogida de datos diseñado para tal fin (anexo 2). Este CRD/eCRD asignaba automáticamente el código identificativo de la farmacia donde se realizaba la demanda y generaba un identificativo anónimo y exclusivo para el farmacéutico. En este CRD se identificaba quién realizaba la demanda: paciente o cuidador y nivel educativo.

Del paciente se registró el sexo, la edad, embarazo/lactancia, tipo de paciente, así como si la demanda se hacía con receta médica privada, con prescripción médica irregular o sin receta (automedicación). Como prescripciones médicas irregulares se consideraron los siguientes casos: informe de urgencias, informe al alta hospitalaria, prescripción verbal/telefónica, insuficiente cantidad para completar el tratamiento, pérdida o rotura de envase, tratamiento prescrito en diferido para situaciones especiales (EPOC, ITU, asma...), profilaxis previa a una intervención y otros casos.

Al finalizar la dispensación el farmacéutico entregaba una hoja de recomendaciones SEFAC sobre el uso correcto de los antibióticos (anexo 3).

Al finalizar cada uno de los periodos de recogida de datos, el farmacéutico anotaba el número total de envases de antibióticos por vía oral del grupo J01 dispensados con la finalidad de conocer el porcentaje de demandas de antibióticos con receta privada, prescripción irregular y automedicación que se producía en cada farmacia.
Análisis estadístico

Parámetros de valoración: los recogidos en el CRD (anexos 1 y 2).

Los análisis descriptivos de las variables continuas se llevaron a cabo mediante medias y desviaciones estándar mientras en las variables categóricas se utilizaron frecuencias.

Para evaluar si existían diferencias estadísticas entre las diferentes variables del estudio en función de las características de los pacientes y de la farmacia se realizaron regresiones logísticas (en variables con respuesta binaria, Sí/NO) o regresiones logísticas ordinales (variables de respuesta múltiple como tipo de demanda).

En las variables de respuesta binaria no se tuvieron en cuenta aquellas demandas que no registraron la respuesta.

Los análisis estadísticos se realizaron para un nivel de confianza del 95\%. Se utilizó el software estadístico STATA MP13.1

\section{Resultados}

Se registraron para realizar el estudio 365 farmacéuticos, la gran mayoría mujeres $(71,8 \%)$ pertenecientes a 247 farmacias.

Un 75,4\% de los farmacéuticos tenía edades comprendidas entre 31 y 60 años. La edad media de los inscritos ha sido $41,8( \pm 11,1)$ años, sin existir diferencias entre hombres $(42,1 \pm 11,5)$ y mujeres $(41,7 \pm 10,9)$. En la tabla 1 se identifican las edades y el sexo de los farmacéuticos participantes. Los farmacéuticos llevaban trabajando en farmacia comunitaria un promedio de 15,3 años, sin existir

Tabla 1 Sexo y edad del total de farmacéuticos registrados en farmacias que han introducido pacientes

\begin{tabular}{|l|r|r|r|c|}
\hline & $\mathrm{n}$ & $\%$ & Media & $\begin{array}{c}\text { Desviación } \\
\text { estándar }\end{array}$ \\
\hline Hombres & 100 & 27,4 & 42,1 & 11,5 \\
\hline Mujeres & 257 & 70,4 & 41,7 & 10,9 \\
\hline Menores de 31 años & 66 & 18,1 & 25,4 & 5,9 \\
\hline Entre 31 y 45 años & 164 & 44,9 & 38,4 & 4,4 \\
\hline Entre 46 y 60 años & 111 & 30,4 & 52,4 & 3,9 \\
\hline Mayores de 60 años & 17 & 4,7 & 64,9 & 3,9 \\
\hline Tota* & 358 & 98,1 & 41,8 & 11,1 \\
\hline
\end{tabular}

* Siete registros (1,9\% del total), 2 hombres, 4 mujeres y 1 sujeto sin registro de sexo, no tienen registrada la edad o tienen una edad registrada inferior a 16 años. Además, un registro (0,3\% del total) no tiene registrado el sexo. Este dato hace referencia al total de farmacéuticos registrados en el estudio que trabajan en farmacias que han participado en el estudio (ver limitaciones). 
Tabla 2 Perfil profesional de los farmacéuticos registrados, edad y años de experiencia

\begin{tabular}{|l|c|c|c|c|}
\hline Puesto & $\mathbf{n}$ & $\%$ & $\begin{array}{c}\text { Media } \\
\text { de edad }\end{array}$ & $\begin{array}{c}\text { Años de } \\
\text { experiencia }\end{array}$ \\
\hline Adjunto/a & 172 & 47,1 & 36,2 & 10,6 \\
\hline Regente & 4 & 1,1 & 46,7 & 14,8 \\
\hline Sustituto/a & 24 & 6,6 & 39,6 & 14,1 \\
\hline Titular & 158 & 43,3 & 48,3 & 21,0 \\
\hline Total & 358 & & & \\
\hline
\end{tabular}

Siete registros (1,9\% del total) no tienen registrado el puesto.

diferencias entre hombres (15,3 años) y mujeres (15,4 años). Un 47\% eran adjuntos con una media de edad de 36,2 años y 10,6 años de experiencia $\mathrm{y}$ un $43,3 \%$ eran titulares con una media de edad de 48,3 años y casi 21 años de experiencia. El perfil de estos farmacéuticos se describe en la tabla 2.

El número de farmacias registradas fue de 247 , se trata de FC repartidas por las 17 comunidades autónomas, es decir, que el estudio abarca toda España, exceptuando Ceuta y Melilla (figura 1).
Han introducido casos (encuestas) en el estudio un total de 341 farmacéuticos, que trabajan en esas 247 farmacias comunitarias. El número medio de registros realizados por farmacéutico ha sido $16,4( \pm 15,4)$, el farmacéutico que más registros ha realizado ha enviado 86 y el que menos uno. En cuanto al número de registros por farmacia, la media ha sido de 22,6 $( \pm 17,8)$, siendo 95 el número máximo realizado por farmacia y uno el mínimo. 17 registros no tenían farmacéutico registrado y no se han tenido en cuenta en el cálculo de la media.
La comunidad autónoma (CA) que mayor número de encuestas ha realizado ha sido la Comunidad Valenciana $(n=1.053 ; 18,9 \%)$, seguida de la Comunidad Autónoma de Madrid $(\mathrm{n}=932 ; 16,7 \%)$. La media ha sido de $317,8( \pm 317,1) .174$ encuestas no tenían filiación autonómica y no se han tenido en cuenta en el cálculo de la media. Los datos del número de encuestas por CA se encuentran descritos en la tabla 3.

Los farmacéuticos que más registros han realizado en el estudio han sido los titulares $(n=3.193$; $57,3 \%$ ), seguidos de los adjuntos $(\mathrm{n}=1.982 ; 35,6 \%)$ y los sustitutos $(\mathrm{n}=284 ; 5,1 \%)$ (tabla 4$)$. Los farmacéuticos más colaboradores fueron los que tenían edades comprendidas entre los 36 y 50 años $(n=2.154$; $38,6 \%$ y los menos colaboradores los de más de 51 años $(n=1.593$; 28,6\%) (tabla 5).

En cuanto al perfil de las farmacias comunitarias que colaboraron en el estudio, el 65,6\% ( $n=162)$ eran farmacias de barrio, seguidas del 13,8\% $(n=34)$ de farmacias rurales $y$ del 9,7\% $(n=24)$ de farmacias próximas a centros de salud (figura 2).

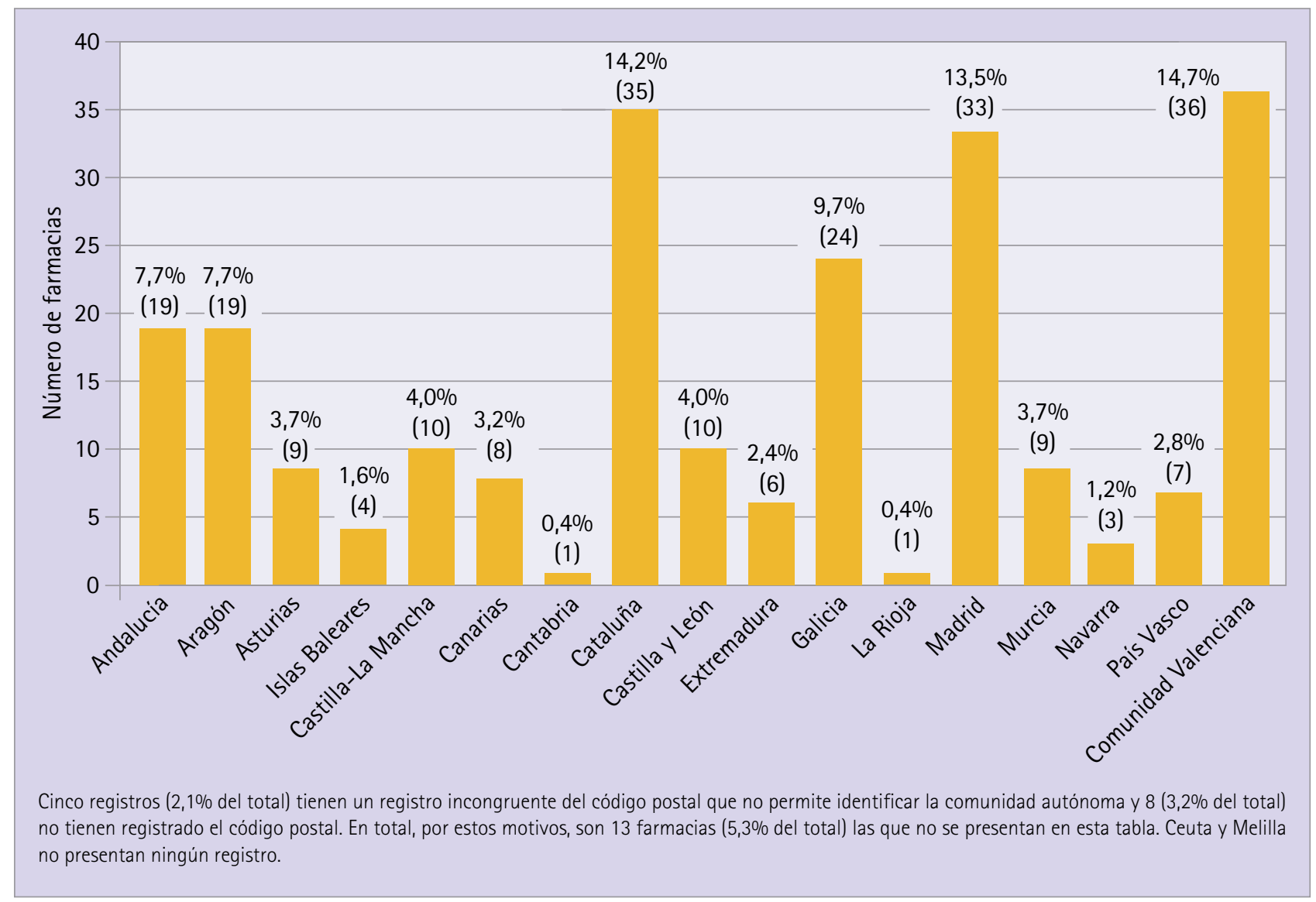


Tabla 3 Media, desviación estándar, máximo y mínimo de encuestas según comunidad autónoma

\begin{tabular}{|c|c|c|}
\hline $\begin{array}{l}\text { Comunidad } \\
\text { Autónoma }\end{array}$ & $\begin{array}{l}\text { Número } \\
\text { de } \\
\text { encuestas }\end{array}$ & Porcentaje \\
\hline Andalucia & 301 & 5,4 \\
\hline Aragón & 276 & 5,0 \\
\hline Asturias & 125 & 2,2 \\
\hline Baleares & 125 & 2,2 \\
\hline $\begin{array}{l}\text { Castilla- } \\
\text { La Mancha }\end{array}$ & 211 & 3,8 \\
\hline Canarias & 174 & 3,1 \\
\hline Cantabria & 21 & 0,2 \\
\hline Cataluña & 670 & 12,0 \\
\hline $\begin{array}{l}\text { Castilla } \\
\text { y León }\end{array}$ & 238 & 4,3 \\
\hline Extremadura & 57 & 1,0 \\
\hline Galicia & 671 & 12,0 \\
\hline La Rioja & 37 & 0,7 \\
\hline $\begin{array}{l}\text { Comunidad } \\
\text { de Madrid }\end{array}$ & 932 & 16,7 \\
\hline $\begin{array}{l}\text { Región de } \\
\text { Murcia }\end{array}$ & 300 & 5,4 \\
\hline Navarra & 74 & 1,3 \\
\hline País Vasco & 138 & 2,5 \\
\hline $\begin{array}{l}\text { Comunidad } \\
\text { Valenciana }\end{array}$ & 1.053 & 18,9 \\
\hline Total & 5.043 & $100,0 \%$ \\
\hline Media (DE) & $\begin{array}{r}317,8 \\
(317,1)\end{array}$ & \\
\hline
\end{tabular}

$174(3,1 \%)$ encuestas no tienen registrada la comunidad autónoma y no se han tenido en cuenta en los cálculos. Máximo y mínimo están destacados en negrita.

Tabla 4 Media, desviación estándar, máximo y mínimo de encuestas realizadas según la categoría profesional del farmacéutico

\begin{tabular}{|l|r|r|}
\hline $\begin{array}{l}\text { Categoría } \\
\text { profesional }\end{array}$ & $\begin{array}{r}\text { Número de } \\
\text { encuestas }\end{array}$ & Porcentaje \\
\hline Adjunto & 1.982 & 35,5 \\
\hline Regente & 41 & 0,7 \\
\hline Sustituto & 284 & 5,1 \\
\hline Titular & 3.193 & 57,3 \\
\hline Media (DE) & $\begin{array}{r}1.375 \\
(1.488,1)\end{array}$ \\
\hline
\end{tabular}

$77(1,4 \%)$ encuestas no tienen registrada la categoria profesional. Máximo y mínimo están destacados en negrita.
Tabla 5 Media, desviación estándar, máximo y mínimo de encuestas realizadas según la edad del farmacéutico

\begin{tabular}{|l|c|c|}
\hline Edades & $\begin{array}{c}\text { Número de } \\
\text { encuestas }\end{array}$ & Porcentaje \\
\hline $\begin{array}{l}\text { Menor de } \\
36 \text { años }\end{array}$ & 1.797 & 32,2 \\
\hline $\begin{array}{l}\text { Entre } \mathbf{3 6} \text { y } \\
\mathbf{5 0} \text { años }\end{array}$ & 2.154 & 38,6 \\
\hline $\begin{array}{l}\text { Mayor de } \\
\mathbf{5 1} \text { años }\end{array}$ & 1.593 & $\mathbf{2 8 , 6}$ \\
\hline $\begin{array}{r}\text { Media (DE) } \\
\begin{array}{r}1.848 \\
(284,0)\end{array}\end{array}$ & \\
\hline
\end{tabular}

$33(0,6 \%)$ encuestas no tienen registrada la edad del farmacéutico. Máximo y mínimo están destacados en negrita.

\section{Discusión}

La resistencia a los antibióticos constituye uno de los mayores desafíos que afronta la medicina en la actualidad. Es una amenaza creciente para la salud pública que afecta a todos los países del mundo debido a que los nuevos mecanismos de resistencia se extienden a escala internacional [20].

El estudio realizado, aunque aquí solo se presenten datos de participación y perfil de farmacias y farmacéuticos participantes, supone el primer diseño de un estudio realizado a nivel nacional en farmacia comunitaria en el que se propone analizar las prescripciones de antibióticos con receta privada y con prescripción irregular, así como la demanda sin receta médica, ya que hasta ahora solo se han realizados estudios a nivel local [21] que incluyen prescripciones incorrectas y automedicación y estudios de demanda por automedicación
[18,22-24]. Las autoridades sanitarias disponen de datos de consumo de antibióticos con receta del Sistema Nacional de Salud y otras entidades públicas, así como de datos estimados de receta privada [25]. El conocer la naturaleza de dichas recetas de medicina privada, la prescripción irregular y la demanda de antibióticos sin prescripción, supone un avance en el conocimiento del uso de antibióticos en nuestro país.

Por prescripciones irregulares consideramos aquellas peticiones de antibióticos previamente a las cuales existe una prescripción médica pero ésta no es la legal en forma de receta médica. Aquí incluimos informes de urgencia y altas hospitalarias, prescripción verbal/telefónica, insuficiente cantidad para completar el tratamiento, pérdida o rotura de envase, entre otras. Consideramos que estas prescripciones deben analizarse separadamente de la automedicación en sentido estricto, debido a que en dichas prescripciones irregulares sí que existe un diagnóstico médico previo.

Además, nuestro diseño incluye cuantificar el porcentaje de pacientes que solicitan antibióticos sin receta al farmacéutico comunitario y analizar los motivos de la automedicación. Hemos pretendido recoger todas las posibles causas que hacen que el paciente se automedique y que se encuentran referidas en la literatura [23,26]. Creemos que con ello lograremos dibujar una radiografía bastante exacta de la demanda de antibióticos sin receta en nuestro país, incluyendo los perfiles del paciente y de la farmacia comunitaria y los motivos más frecuentes que hacen que el paciente se automedique.

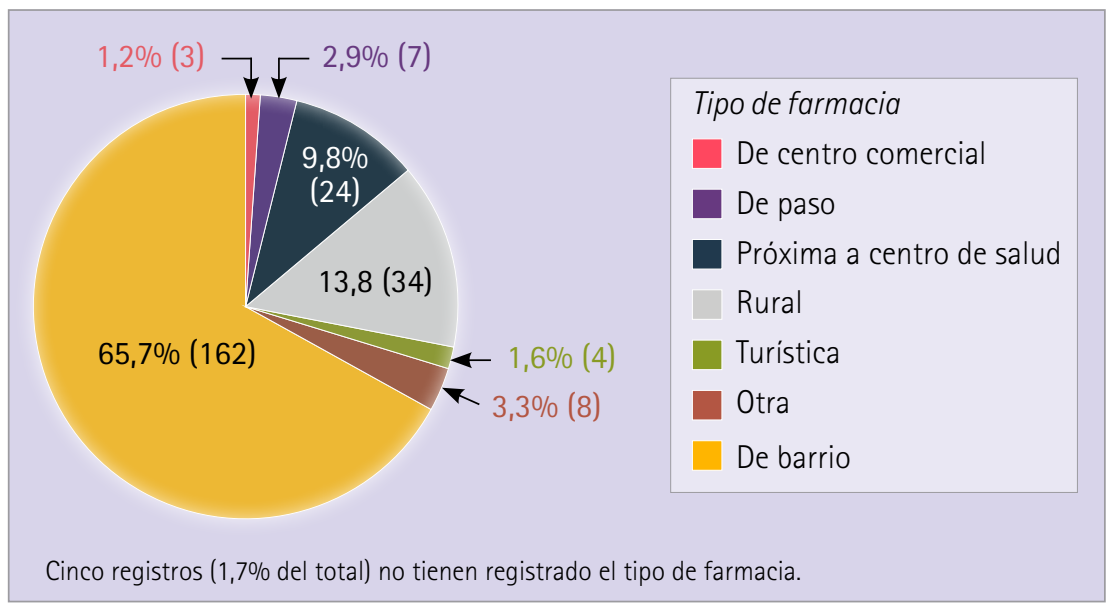

Figura 2 Identificación del tipo de farmacia 
La metodología del estudio se basa principalmente en la utilizada en la tesis doctoral "Estudio de la demanda de antibióticos sin receta en la oficina de farmacia. Papel del farmacéutico en la automedicación" [18] con algunas diferencias. Como en la tesis, se recogieron datos durante cuatro semanas, una en cada estación del año (201617) para así evitar el sesgo estacional.

El número total de farmacias participantes corresponde al 1,1\% del total de farmacias existentes en España [27], si bien hay que tener en cuenta que en este estudio solo han participado farmacias comunitarias cuyos titulares son socios de SEFAC [28], lo que representa un 10,8\% de participación de socios, más alta que en otros estudios similares realizados [18]. La participación por CA es similar a la de otros estudios de investigación con pacientes realizados por SEFAC [29].

Los farmacéuticos comunitarios de Comunidad Valenciana han sido los que más registros han aportado al proyecto, al igual que en otros estudios [18,29,30].

El tipo de farmacia es importante para comprobar si tanto la demanda como la intervención son diferentes según el tipo de farmacia. La idea básica es que en farmacias en las que se puede hablar de "clientes habituales" va a ser más fácil realizar una intervención farmacéutica. Las categorías de tipo de farmacia en la tesis fueron "rural”, "de barrio", "turística”, “zona comercial" y "cercana a un ambulatorio". Además, estos 3 tipos de farmacias (de barrio, rural y cercana a un ambulatorio) fueron las que también más colaboraron por este orden en la tesis del Dr. Luis Salar. En nuestro caso, hemos considerado los mismos tipos de farmacia que estaban en la tesis, a los cuáles hemos añadido la farmacia "de paso" y la farmacia dentro o próxima a un centro comercial, aeropuerto, estación de ferrocarril, estación de autobús... La participación mayoritaria en nuestro estudio ha sido en las farmacias "de barrio", aunque con una cifra mayor que la participación en otros [18,26,29].

La participación femenina fue casi el triple que la masculina, en consonancia con el número de mujeres ejercientes en farmacia comunitaria en España [27].

La edad media de los farmacéuticos participantes (41,8 años) es similar a la de otros estudios recientes
(41,0 años) [29], aunque es algo mayor que en el estudio de referencia utilizado en el diseño de este estudio (38,1 años) [18]. Los titulares tienen más edad que los adjuntos y más años de experiencia y son los que más registros realizan, esto está en consonancia con el perfil mayoritario de los socios de SEFAC [28].

Las limitaciones del presente trabajo son las propias de un estudio de corte transversal que no realiza una aleatorización de farmacéuticos $\mathrm{y}$ usuarios $\mathrm{y}$, por tanto, no permite establecer una relación causa-efecto entre las asociaciones encontradas. Además, es probable que hayan participado los farmacéuticos más motivados, sin embargo, esto no resta validez a los resultados, ya que estos ejercen en todas las CCAA y con diferentes perfiles dentro de las farmacias comunitarias y además la metodología de los análisis realizados proporciona fortaleza al estudio, por lo que entendemos que los datos obtenidos son razonablemente representativos y pueden ser extrapolables a la situación real de las demandas de antibióticos en las farmacias comunitarias de España. En cuanto a la recogida de datos, hubo farmacéuticos que se registraron en el eCRD de farmacéuticos (anexo 1) pero no llegaron a participar $(n=24 ; 7 \%)$. Por ello, la información sociodemográfica relacionada con los farmacéuticos hace referencia a aquellos farmacéuticos registrados en la eCRD de farmacéuticos que trabajan en farmacias que han participado en el estudio (anexo 1).

\section{Conclusiones}

Los farmacéuticos inscritos en este estudio realizado por primera vez a nivel nacional para cuantificar y analizar las prescripciones de antibióticos que llegan a la farmacia comunitaria firmada por médicos que ejercen la sanidad privada, así como las prescritas de manera irregular y la demanda para automedicación, son mayoritariamente adjuntos y pertenecientes al sexo femenino.

Los farmacéuticos más participativos son titulares, que han realizado más de la mitad de los registros. Si no tenemos en cuenta la categoría profesional, los más colaborativos tienen edades entre 36 y 50 años.

Las CCAA con mayor número de farmacias participantes han sido Co- munidad Valenciana, Cataluña y Madrid y las que más han registrado han sido las farmacias de la Comunidad Valenciana.

Las farmacias tipificadas como de barrio han sido mayoritarias y las que han registrado mayor número de casos.

\section{Responsabilidades éticas}

Protección de personas y animales

Los autores declaran que para esta investigación no se han realizado experimentos en seres humanos ni en animales.

\section{Confidencialidad de los datos}

Los autores declaran que han seguido los protocolos de su centro de trabajo sobre la publicación de datos de pacientes.

\section{Derecho a la privacidad $y$ consentimiento informado}

Los autores declaran que en este artículo no aparecen datos de pacientes y todos los participantes aceptaron voluntariamente ser incluidos en el estudio.

\section{Agradecimientos}

A todos los farmacéuticos participantes del estudio:

Adama Peña Vera, Agustín Bayón Cores, Alba Ramírez Rosales, Albert Vilá Badia, Alberto Barrionuevo Torres, Alejandro Díaz Álvarez, Alexandra Ñeco Aladid, Alfonso Carlos Navarro Labrid, Alfonso López Ruíz, Amalia García-Delgado Morente, Amparo Calero Barreda, Ana Arce Cadierno, Ana Barbará Ruíz Labrador, Ana Bretón de la Cal, Ana de Frutos del Río, Ana del Carre López, Ana García Pineda, Ana Hernández Gómez, Ana María Mateos Lardiés, Ana Matheo Iglesias, Angélica Santamaría Bárcena, Anna Catalá Cerdán, Anna Gonzalez Ruíz, Anna Icart de Bofarull, Antonia Fornaris Ramis, Antonio de Marcos Simón, Antonio José Lillo Serrano, Antonio Luis Delgado Márquez, Aracely Ribera Moro, Ares Vergoños, Aurora Avellano Albendea, Aurora Avellano Albendea, Baltasar González Sánchez, Bartomeu Amengual Riera, Beatriz Rubio Sánchez, Beatriz San Pedro Rodríguez, Beatriz Sánchez Carrasco, Belén Parra Escartín, Belén Parra Escartín, Blanca Yubero, Camino Hernández Iglesias, Carlos Fernández Pérez, Carlos López Díaz de Rada, Carme Gayà Mascaró, 
Carme Mestres Català, Carmen Bacelo Prada, Carmen Giménez Villanueva, Carmen Juan Ferrándis, Carmen Leandro Gutiérrez de Ceballos, Carmen Redondo Sampedro, Carmen Romero Galván, Carmen Rosa Edrosa Alpizar, Carolina Martínez Adán, Catalina Sanfelix Pérez, César Pla Mira, Christian Ibáñez Verdegal, Cinta Lobato Rodríguez, Concepción Gómez Sáez, Concepción Ortego Albarrán, Concepción Vicedo Gómez, Cristina Bañón Roldan, Cristina Cañete Toratajada, Cristina Casas Verdés, Cristina de Diego, Cristina Fortúnez Garea, Cristina Latorre Esbri, Cristina Lobato Rodríguez, Cristina Sánchez García, Damián Vidarte Vázquez, Dayana Jácome Celi, Diego Segurado Zurdo, Digna Ramos Galindo, Dolors Raja García, Eduardo Navarro Labrid, Eider Bujanda, Elena Díaz Cervero, Elena Inocencio Morales, Elena Pérez Belda, Elisabeth March Vila, Eloi Merencio Naudin, Elvira García Llaneza, Encarna Ramírez López, Enrique Pepiol Salom, Esperanza Díaz Palomino, Ester Boldú Capdevila, Fátima Nieto del Amor, Félix Mariblanca Romero, Fernando Aguilera Castro, Fernando Ferrer Estrela, Fernando Mora Pérez, Fernando Mud Castello, Floro Andrés Rodríguez, Francisca Ruiz Lozano, Francisco Alonso Deibe, Francisco Borja Olmedo Aguilera, Francisco Crespo Sánchez, Francisco de Sales Cuenca García-Minguillán, Francisco Javier de Miguel Rekalde, Francisco Javier Diéguez Couso, Francisco Javier Plaza Zamora, Francisco Sastre García-Rojo, Gemma Vila, Germán López López, Giselle Ochoa Musso, Glòria Montané Bombardó, Glòria Piera Serra, Gonzalo Álvarez Pérez, Guillermo Bagaría de Casnaova, Helena Salguero Romero, Herminia Panadero Denia, Idoya Jorge Moral, Ignacio Compairé Bergua, Ignacio Salar Valverde, Inés Mera Gallego, Inmaculada Díaz Varela, Inmaculada Gonzalez Pérez, Irene Escudero Rivera, Irene Gragea Álvarez, Irene Jaraíz Magariños, Isabel Brea Hernando, Isabel Coira Nieto, Isabel Senante Lop, Isabel Talavera Ginés, Iván Busto Domínguez, Jacinta del Campo Molina, Jaime Ruiz de Castañeda Gallego, Javier Reig López, Jessica Espiña Cordero, Jessica Sánchez Mudarra, Jesús Carlos Gómez Martínez, Jesús Colino Sendin, Joana $\mathrm{M}^{\mathrm{a}}$ Borràs Seguí, Joaquina Huarte, Jorge Granados Flores, Jorge Porcel García, José Chacón Hernández, José Espinosa Navarro, José Iborra Bou, José María
Martin Blanco, José Palo Serrano, José Pavón Soldevila, Josefa Castro Leis, Josefa Sanmartín Martí, Juan Antequera R-Rabadán, Juan Miguel de la Rubia Cómos, Laia Matarranz Torres, Laura Caparros Linares, Laura Galindo Juberías, Laura Gomà Llairó, Laura López Pardo, Laura Murillo Moya, Laura Tuset, Leire Andraca Iturbe, Leyre de la Iglesia Santamaría, Lola Martin Jimenez, Lorena Casanova Valera, Lourdes Luisa Morro Felipe, Lourdes Romero Toledo, Luis Felipe Ruiz de Castañeda Gallego, Luis Hernández Tomás, Luis Méndez Dávila, Luis Montalbán Soler, Lydia Sánchez, María Dolores Cicuendez Rodríguez, María Mar Velert Vila, María Sonia Fabra Vicente, $\mathrm{M}^{\mathrm{a}}$ Ángeles Escudero Requejo, Ma Ángeles Sala Doló, Ma Ángeles Seminario Echeverría, $\mathrm{M}^{\mathrm{a}}$ Asunción Garzás Garzás, $\mathrm{M}^{\mathrm{a}}$ Belén Morcuende Timón, $\mathrm{M}^{\mathrm{a}}$ Carmen Castro Díaz, Ma Carmen Cubedo Gil, $\mathrm{M}^{\mathrm{a}}$ del Puerto de la Fuente Arjona, $\mathrm{M}^{\mathrm{a}}$ José Jimenez Moreno, Ma Piedad Alonso Jiménez, Ma Pilar García Fernández, Ma Pilar Rodríguez Martínez, $\mathrm{M}^{\mathrm{a}}$ Rosario Hernández Marrero, $\mathrm{M}^{\mathrm{a}}$ Rosario Hernández Marrero, $\mathrm{M}^{\mathrm{a}}$ Teresa Peris Molina, Ma Victoria Arniges Gómez, Ma Carmen Anguita Fernández, $\mathrm{M}^{\mathrm{a}}$ Concepción García Vivancos, $\mathrm{M}^{\mathrm{a}}$ Elena Melguizo Jiménez, Manuel Adell Aledón, Manuel Adell Alegre, Manuel Andrades Ponc, Manuel Castillo López, Manuel Cubedo Ventura, Manuel Gómez Galindo, Manuel Luengo Fajardo, Manuel Montes Robles, Mar Gracias Monserrat, Margarita Olagorta de Prado, Margarita Pérez Vilariño, María Arnau Bonachera, María Carmen Girón Duch, María del Pilar González Pérez, María Díez Garrido, María Echeveste Gonzalez, María Elena Saiz Izquierdo, María Esperanza Hernández Rodríguez, María Guadalupe González Pérez, María Jesús Gordillo Abalos, María José Alonso Osorio, María José Cabré Menendez, María José Gómez López, María José Palop Lluch, María José Rodríguez Moncho, María Josefa Cordero Pérez, María Josep Sanchís Boronat, María Lago Preciado, María Lourdes Ogallar Martin, María Luisa Alonso Núñez, María Martin Bejarano, María Montserrat Lage Piñón, María Pilar Samper Casafranca, María Teresa Alén de la Torre, María Teresa Mateos Lardiés, María Teresa Pelaez, Marian Egozcue, Maricarmen Magro Horcajada, Marieta Cano Congost, Marta Amat Flinch, Marta Burniol García, Marta Carrace- do, Marta Ferrer Far, Marta González de la Fuente, Marta Lázaro Navarro, Marta Ramos Parra, Marta Rodríguez Haro, Marta Serra Saval, Marta Terciado Valls, Martin Ramírez de Diego, Matilde Lacarra Calvo, Mercedes Arias Puente, Mercedes Cervero Jiménez, Mercedes Cuéllar García, Meritxell Junyent, Miguel Álvarez Soaje, Miguel Rivas Cabrera, Milagros Salinas Martí, Mireia Curto Gonzalvo, Mireya Suárez Hurlé, Miriam Macías Bravo, Miriam Martín González, Montserrat Compte Ramisa, Montserrat Fernández Ropero, Montserrat Mazón Barrio, Montserrat Triadu Sanjuan, Nerea Acuña Elvira, Nerea Queiro Candal, Nidia Esther Díaz Albertos, Nina Villasusocores, Noelia Penades Pérez, Nuria Montero Sánchez, Nuria Muñoz Muñoz, Olga Padilla, Pablo García Salgado, Pablo Mora Ortiz de Apodaca, Paqui Moreno Fernández, Patricia Alonso Lovera, Patricia Guerrero Pérez, Patricia Isabel Morales Hernández, Patricia Román Mascaró, Paula Briones Amor, Pedro Gabriel Gil Espallardo, Pedro Rodríguez Moreta, Pepa Cortés Botella, Pilar Galindo Gallardo, Pilar Ladrón De Guevara, Pilar Méndez Mora-Figueroa, Rafael Martínez Olmedo, Ramón Piera de Ciurana, Raquel Aceituno Gómez, Raquel Cámara Rica, Raquel del Moral, Raquel Fernández Franco, Raquel García Fuentes, Raquel Lorenzo Picazo, Raquel Romo Fernández, Raúl Luque del Moral, Rebeca Escribano Molinero, Rocío López-Ybarra Flores, Rocío Navarro Martin, Rosa Ana Torrecillas Navarro, Rosa Llull Vila, Rosa Prats Mas, Rosalía López Llorca, Rosana Valles Foix, Rubén Queimaño Costas, Salvador Tous I Trepat, Sandra Carrasco López, Sara Marín Boloqui, Sara Mud Castello, Sara Rojas Pérez, Sergi Larena Grau, Silvia Lara Afonso Trujillo, Susana Gregorio Mazo, Susana Lucas Male, Susana Martínez García, Susana Serrano Sarasa, Teresa Duarte Vázquez, Teresa Eyaralar Riera, Teresa Gil Alegre, Tomás Codesal Gervás, Tomás Martínez Rueda, Txell Junyent Mestre, Valentín Robledano Cortes, Vanessa Piera Villora, Vanna Verduci, Verónica López Pallín, Vicenç Alemany Reus, Vicente Faus Felipe, Vicente J. Baixauli Fernández, Vicente Porcar Jover, Victoria Morgado Enríquez, Violeta López Lemes, Xavier Boleda Relats, Xavier Subirana Freixas, Yolanda Forcadell Berenguer, Yvonne Herrero Tendero, Zeneida Perseguer Torregrosa. 
Anexo 1. Hoja de registro de las farmacias comunitarias que han colaborado (CRD)

\section{A. DATOS DEL FARMACÉUTICO}

1. Sexo:

O Hombre

O Mujer

2. Edad: años

3. Años de experiencia profesional en farmacia comunitaria: años

4. Puesto que desempeña en la farmacia:

O Farmacéutico/a titular

O Farmacéutico/a regente

O Farmacéutico/a sustituto/a

O Farmacéutico/a adjunto/a

\section{B. DATOS DE LA FARMACIA COMUNITARIA}

5. Código postal

6 Marque el tipo en el que clasifica su farmacia (en base a la población a la que abastece y a su ubicación geográfica). Es posible marcar más de una opción:

- Farmacia de barrio: la mayor parte de los usuarios son habituales y conocidos

- Farmacia de paso: la mayor parte de los usuarios son desconocidos, no habituales

- Farmacia rural: en poblaciones de menos de 5000 habitantes y/o sin centro de salud

- Farmacia turística: con un fuerte componente de usuarios en situación de desplazados

- Farmacia dentro o próxima a un centro comercial, aeropuerto, estación de ferrocarril, estación de autobús.

- Farmacia próxima a centro de salud

- Otras 
Anexo 2. Hojas de recogida de datos de los demandantes de antibióticos

1. ¿Quién realiza la demanda?: Paciente Cuidador

2. Sexo paciente: Hombre Mujer

3. Edad: paciente

$<1$ año

$1-4$ años

$5-14$ años

$15-24$ años

$25-44$ años

$45-65$ años

$66-75$ años

$>75$ años

4. Embarazo, lactancia

5. Nivel educativo: sin estudios, estudios primarios, estudios secundarios, estudios universitarios.

6. Tipo de paciente: habitual o esporádico

7. ¿Hay una receta médica?

Si. Pasar a demanda de antibiótico con receta (1)

No. Pasar a demanda de antibiótico sin receta:

¿Hay prescripción pero no receta? (2)

¿Es automedicación? (3)

\section{DEMANDA DE ANTIBIÓTICO CON RECETA MÉDICA}

CN medicamento prescrito:

Dosis, posologia, duración del tratamiento

Tipo de receta:

\section{Receta privada}

Receta privada que no cumple normativa vigente

Criterios de no dispensación: alergia, contraindicaciones, duplicidades.

¿Quién lo ha prescrito?

Dentista, pediatra, urólogo, ginecólogo, dermatólogo, médico de AP, digestivo, neumólogo, otorrinolaringólogo, otros.

¿Para qué se lo han prescrito?

- Infecciones Tracto Superior: otitis, sinusitis, faringoamigdalitis, resfriados.

- Infecciones odontógenas

- Infecciones Tracto Inferior: neumonía, gripe, bronquitis, exacerbación EPOC.

- Infecciones de piel y partes blandas.

- ITU

- Infecciones Genitales

- Gastroenteritis/diarrea del viajero.

- Otras

¿Es tratamiento o profilaxis?

¿Es tratamiento de inicio?

- ¿Sabe para qué lo va a usar?

- ¿Sabe cuánto ha de usar?

- ¿Sabe durante cuánto tiempo lo va a usar?

- ¿Sabe cómo lo tiene que usar? (analizar si existen condiciones especiales de empleo/manipulación y/o conservación).

- ¿Conoce las advertencias de inefectividad y seguridad?

¿Es tratamiento de continuación?

- ¿Le han cambiado algo? (pauta, dosis, etc.).

Si la respuesta es afirmativa, realizará las mismas preguntas que si se tratara de inicio de tratamiento.

Si la respuesta es negativa preguntará: ¿Cómo le va el tratamiento?, y ¿Tiene algún problema con el tratamiento? Identificación de PRM (Según Foro de Atención Farmacéutica en FC)

- Características personales

- Contraindicación

- Dosis/pauta/duración no adecuada

- Duplicidad

- Interacciones

- Medicamento no necesario

- Probabilidad de efectos adversos

- Problema de salud insuficientemente tratado 
Identificación de RNM (Según Foro de Atención Farmacéutica en FC)19

- Necesidad:

- Problema de salud no tratado

- Efecto de medicamento innecesario

- Efectividad

o Dosis o duración menor de la necesaria

o Interacciones que aumenten/disminuyan la concentración del medicamento en sangre

- Seguridad

- Medicamento contraindicado

o Reacciones adversas

o Interacciones que aumenten la concentración del medicamento en sangre provocando inseguridad en el uso.

¿Conoce que el antibiótico sobrante debe depositarse en el punto SIGRE? Si/No

Ofrecer IPM

Ofrecer información sobre uso de antibióticos (ANEXO III)

Número de envases dispensados: 1 ó 2

\section{DEMANDA DE ANTIBIÓTICO CON PRESCRIPCIÓN IRREGULAR}

$\mathrm{CN}$ medicamento prescrito

¿Por qué demanda el medicamento?

- Informe de urgencias

- Informe al alta hospitalaria

- Prescripción oral / telefónica (dentista)

- Insuficiente cantidad para completar el tratamiento

- Pérdida o rotura de envase

- Tratamiento prescrito en diferido para situaciones especiales (EPOC, ITU, asma,...)

- Profilaxis previa a una intervención

- Otras

¿Para qué lo demanda?

- Infecciones tracto superior: otitis, sinusitis, faringoamigdalitis, resfriados.

- Infecciones odontógenas

- Infecciones tracto inferior: neumonía, gripe, bronquitis, exacerbación EPOC.

- Infecciones de piel y partes blandas

- Infecciones tracto urinario (ITU)

- Infecciones genitales

- Gastroenteritis/diarrea del viajero.

- Otras

¿Quién refiere el paciente que ha hecho la prescripción?

- Dentista, pediatra, urólogo, ginecólogo, dermatólogo, médico de AP, digestivo, neumólogo, otorrinolaringólogo, alergólogo, otros.

\section{Intervención: REMITIR AL MÉDICO}

- Ofrecer información sobre uso correcto de antibióticos

Identificación de PRM (Según Foro de Atención Farmacéutica en FC)

- Problema de salud insuficientemente tratado

Identificación de RNM (Según Foro de Atención Farmacéutica en FC)

- Necesidad:

- Problema de salud no tratado 


\section{DEMANDA DE ANTIBIÓTICO SIN PRESCRIPCIÓN Y SIN RECETA (AUTOMEDICACIÓN)}

Medicamento solicitado:

Principio activo, marca (CN) o sin especificar (dame un antibiótico para...)

¿Por qué demanda el medicamento?

- Lo ha utilizado antes para los mismos sintomas

- Escasez de tiempo para acudir a la consulta

- Dificultad para acceder a la consulta (incomodidad)

- Le preocupa mucho su estado de salud

- El antibiótico cuesta muy poco

- El antibiótico no entra en el seguro

- Recomendación de un no profesional / internet

- El paciente considera que debe seguir con el tratamiento

- Otras

- No lo justifica

¿Para qué lo demanda?

- Infecciones Tracto Superior: otitis, sinusitis, faringoamigdalitis, resfriados.

- Infecciones odontógenas

- Infecciones tracto inferior: neumonía, gripe, bronquitis, exacerbación EPOC.

- Infecciones de piel y partes blandas

- Infección del tracto urinario (ITU)

- Infecciones genitales

- Gastroenteritis/diarrea del viajero

- Para tenerlo en casa

- Otras

\section{Intervención:}

- Remitir al médico

- Ofrecer información sobre uso correcto de antibióticos (ANEXO III)

- Dispensar otro medicamento (Indicar CN)*

- Medidas higiénico-dietéticas*

Identificación de PRM (Según Foro de Atención Farmacéutica en FC)

- Medicamento no necesario (no necesita el antibiótico solicitado)

- Problema de salud insuficientemente tratado (se indica otro medicamento o se deriva al médico para que prescriba el antibiótico)

Identificación de RNM (Según Foro de Atención Farmacéutica en FC)

- Necesidad:

- Efecto de medicamento innecesario

o Problema de salud no tratado 
Anexo 3. Hoja de recomendaciones SEFAC sobre el uso correcto de antibióticos

Recomendaciones de la Sociedad Española de Farmacia Familiar y Comunitaria a la población.

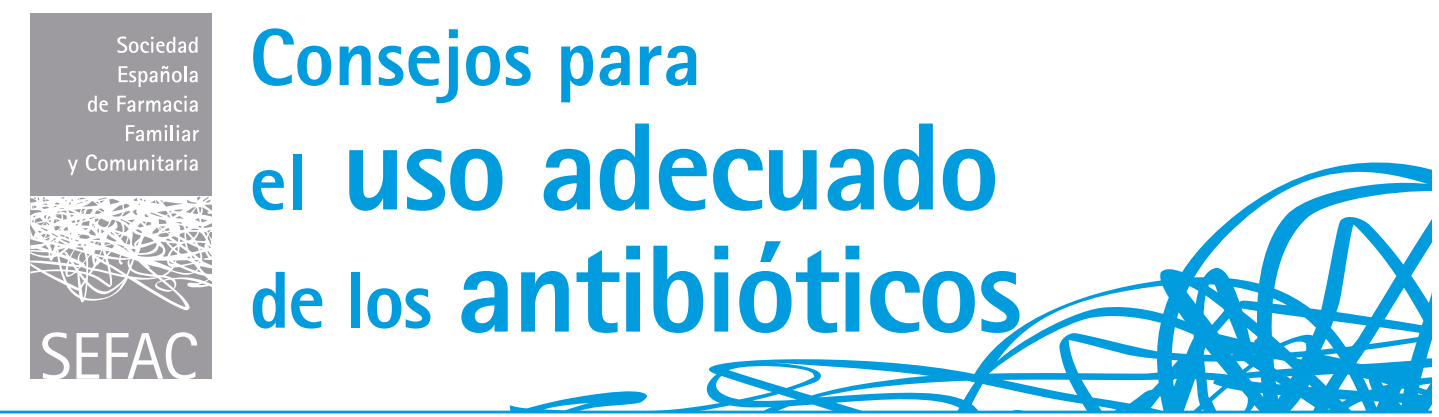

\section{Un problema que se resiste}

El uso de los antibióticos constituye uno de los mayores logros terapéuticos de la Historia de la Medicina. Gracias a ellos podemos curar enfermedades que hasta principios del siglo XX eran mortales. Antes de su descubrimiento, el 90 por ciento de los niños que padecían una meningitis bacteriana moría y los que sobrevivían padecían discapacidades graves, sordera o retraso mental. Las infecciones de garganta y otras como tuberculosis, neumonía o tosferina provocaban normalmente la muerte. Además, los antibióticos han contribuido de forma significativa al progreso en campos como los trasplantes de órganos, la supervivencia de bebés prematuros y de pacientes inmunodeprimidos o la cirugía de material protésico y los catéteres vasculares, donde las infecciones son especialmente prevalentes e importantes. Sin embargo, las resistencias bacterianas a los antibióticos han pasado de ser una amenaza a ser una realidad y constituyen un problema mundial de Salud Pública que implica a pacientes, a sanitarios, a las Administraciones, a la industria farmacéutica, etc.

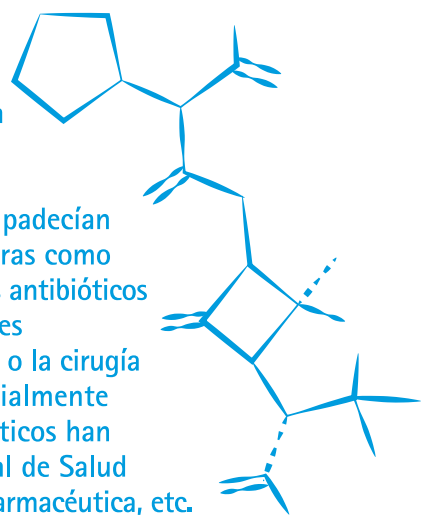

\section{Recomendaciones}

LOS ANTIBIOTIICOS SÓLO PUEDEN SER DISPENSADOS EN LA FARMACIA CON RECETA MÉDICA. Por tanto, recuerde que siempre será el médico el que decida su posible uso.

UTILICE LOS ANTIBIÓTICOS DE FORMA ADECUADA. Tanto su médico como su farmacéutico le explicarán que, para que sean efectivos, debe respetar el horario de las tomas y finalizar el tratamiento aunque note mejoria en los sintomas. Si no lo hace asi, las bacterias pueden crear resistencias a ese antibiótico y, por tanto, no le hará efecto.

LOS ANTIBIÓTICOS SIRVEN PARA TRATAR INFECCIONES PROVOCADAS POR BACTERIAS y no son eficaces frente a infecciones producidas por virus, hongos o por parásitos. En caso de sospecha de infección, acuda a su médico para que diagnostique el problema y adopte las medidas terapéuticas oportunas.

SIGA AL PIE DE LA LETRA LAS INSTRUCCIONES que le dé su farmacéutico sobre cómo utilizar los antibióticos.

SI ES USTED ALÉRGICO A ALGÚN ANTIBIÓTICO, hágaselo saber tanto a su médico como a su farmacéutico.

ALGUNOS ANTIBIÓTICOS PUEDEN PRODUCIR EFECTOS ADVERSOS como reacciones alérgicas o diarreas. Ante una reacción alérgica grave (ahogo o hinchazón en la cara o en otra parte del cuerpo) acuda a un servicio de urgencias. Ante una diarrea de más de dos dias o una reacción alérgica leve, consulte a su médico o a su farmacéutico.
CONSERVAR LA MEDICACIÓN SOBRANTE AUMENTA EL RIESGO DE UTILIZACIÓN INADECUADA posterior porque el paciente decida automedicarse. Además, incluso en caso de una nueva prescripción médica el fármaco sobrante puede estar caducado o en malas condiciones de conservación. Por tanto se recomienda que deposite en el punto Sigre de su farmacia la medicación antibiótica sobrante.

NUNCA UTILICE, NI RECOMIENDE A OTROS, MEDICACIÓN SOBRANTE DE SU BOTIQUíN o de otros botiquines aunque esté convencido de que los síntomas son los mismos que en otra ocasión anterior. Es muy frecuente que sintomas aparentemente iquales escondan problemas de salud diferentes.

NO PRESIONE AL MÉDICO PARA QUE LE RECETE UN ANTIBIÓTICO, ni al farmacéutico para que se lo dispense sin receta médica. Confie en su criterio profesional.

RECUERDE OUE LAS MISMAS PRECAUCIONES que adoptamos con las personas en relación con el uso adecuado de los medicamentos antibióticos DEBEN APLICARSE A NUESTRAS MASCOTAS. Por tanto, evite medicar a su mascota sin la preceptiva receta de un veterinario. 


\section{Preguntas frecuentes}

\section{¿Qué son las resistencias bacterianas} a los antibióticos?

Es la capacidad que tienen las bacterias para protegerse de los antibióticos con los que pretendemos eliminarlas, por lo que no mueren y se convierten en "bacterias resistentes". Desgraciadamente, en nuestro entorno ya existen bacterias que son resistentes a casi todos los antibióticos conocidos (Ilamadas multirresistentes) y que causan la muerte a más de 25.000 pacientes al año en la Unión Europea.

¿Cómo aparecen las resistencias? Las resistencias son resultado del mal uso de los antibióticos. Aparecen cuando el contacto del antibiótico con la bacteria a la que queremos matar es insuficiente en dosis y/o en tiempo, ya que ésta aprende a defenderse del antibiótico y se vuelve resistente a él. Por esto es crucial cumplir a rajatabla tanto la dosificación marcada como la duración del tratamiento. Existe la falsa creencia de que un paciente se puede "hacer resistente" a un antibiótico. La realidad es que la resistencia la presenta la bacteria cuando aprende a defenderse de un determinado antibiótico.

\section{¿Por qué las resistencias bacterianas} preocupan tanto?

Porque cada vez es mayor el número de bacterias resistentes a los antibióticos $y$, por tanto, cada vez es más complicado tratar infecciones, heridas y lesiones que se agravan $e_{\text {, incluso, }}$ pueden producir la muerte del paciente. Por ejemplo, un cirujano necesita antibióticos para operar sin riesgos de infecciones añadidas. Si no tuviera antibióticos eficaces, no podría operar a un paciente.

\section{¿Cómo se propagan las bacterias} resistentes?

Se propagan, al igual que el resto de bacterias, de persona a persona o a través de un animal, por vía aérea, por contacto físico, por gotas de saliva o por los alimentos.

Creo que se exagera con el problema de Ios antibióticos. Si decido tomarlos sin consultar al médico, el problema es mío ya que lo más que puede pasar es que no me cure.

Esto no es del todo cierto. Cuando un paciente no usa el antibiótico correctamente asume riesgos personales $y$, además, pone en riesgo la salud de toda la comunidad, pues fomenta la creación de bacterias resistentes que pueden causar serios problemas de salud a otras personas.
Los antibióticos suelen provocarme un poco de diarrea. ¿Puedo hacer algo para evitarlo?

Los antibióticos tratan de acabar con bacterias hostiles aunque también destruyen parte de nuestra flora bacteriana intestinal, necesaria para el buen funcionamiento de nuestro organismo. Aunque tomar un yogur diario puede ayudar a restablecer la flora intestinal, existen preparados específicos basados en el aporte de prebióticos y probióticos. Consulte a su farmacéutico.

Vengo de urgencias y el médico me ha dado este informe para que me dispense un antibiótico. ¿Me lo puede dar?

El único documento oficial que habilita al farmacéutico a dispensar un antibiótico es, según la legislación vigente, la receta médica que cumpla los requisitos que marca el Real Decreto de Receta Médica. En las farmacias no se puede aceptar ningún otro documento aunque sea un informe de urgencias, un informe de alta hospitalaria ni una receta en cualquier otro formato. Tampoco es legal dispensar un medicamento prescrito telefónicamente, algo frecuente en el caso de los dentistas. Parece obvio que se trata de ineficiencias del sistema sanitario, que padecen el paciente y también el farmacéutico y que deseamos que en algún momento puedan ser resueltas por las Administraciones sanitarias.

Me duele la garganta, tengo fiebre y estoy muy congestionado. ¿Me hará falta tomar antibiótico?

La mayoría de los procesos de vías respiratorias altas es provocado por virus y no por bacterias. Los sintomas que le ocurren muy posiblemente se deben a un proceso vírico, por lo que no está indicada la utilización de antibióticos, que sólo se usan frente a bacterias. Probablemente su farmacéutico le recomendará un medicamento para reducir los síntomas hasta que remita el proceso por sí solo.

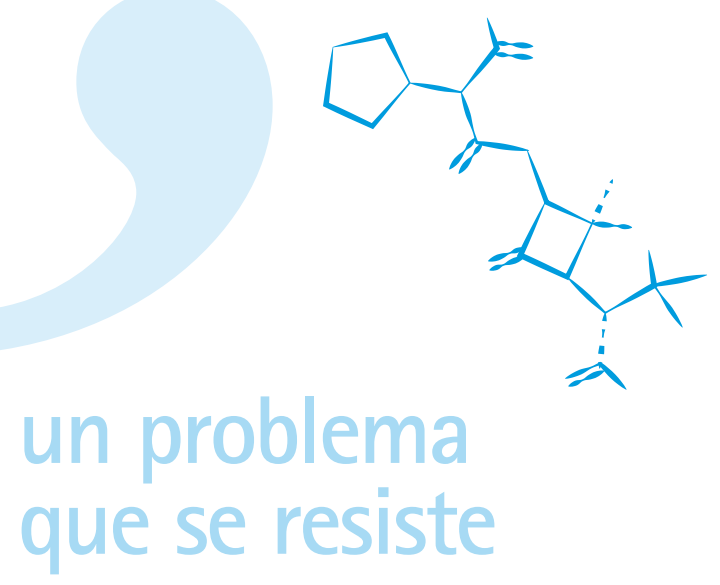

Si quiere más información puede consultar a su farmacéutico de confianza. 


\section{Referencias bibliográficas}

1. Fleming A. On the Antibacterial Action of Cultures of a Penicillium with Special Reference to their Use in the Isolation of B. influenzae. Br J Exp Pathol. 1929; 10(3): 226-36.

2. Lozano R, Naghavi M, Foreman K, Lim S, Shibuya K, Aboyans V, et al. Global and regional mortality from 235 causes of death for 20 age groups in 1990 and 2010: a systematic analysis for the Global Burden of Disease Study 2010. Lancet. 2012; 380:2095-128. doi:10.1016/S0140-6736(12)61728-0

3. Pagalilauan GL, Limaye AP. Infections in transplant patients. Med Clin North Am. 2013; 97: 581-600. doi:10.1016/j. mcna.2013.03.002

4. González-Zorn B. Resistencias a Antibióticos: Vuelta al siglo XIX. Jornada del Día Europeo para el Uso Prudente de los Antibióticos. [Internet]. Madrid: Agencia Española de Medicamentos y Productos Sanitarios; 2015. [Consultado 29/08/2016]. Disponible en: https://www.aemps.gob.es

5. Organización Mundial de la Salud. Antimicrobial Resistance Global Report on Surveillance. [Internet]. Geneva; 2014. [Consultado 07/10/2016]. Disponible en: http://apps.who.int/iris/ bitstrem/10665/112642/1/978924156 4748_eng.pdf?ua = 1

6. 0'Neill J. Tackling drug-resistant infections globally: final report and recommendations. The review on antimicrobial resistance. [Internet]. Londres; 2016. [Consultado 07/10/2016]. Disponible en: https://amr-review. org/sites/default/files/ 160525 Final\%20paper_with\%20cover.pdf

7. Reunión de alto nivel sobre la resistencia a antimicrobianos. Organización de las Naciones Unidas. 71ª Asamblea General de la ONU. [Internet] Nueva York; 2016. [Consultado 07/10/2016]. Disponible en: https://www.un.org/ press/en/2016/ga11825.doc.htm

8. Organización Mundial de la Salud. 51 a Asamblea Mundial de la Salud. Enfermedades emergentes y otras enfermedades transmisibles: resistencia a los antimicrobianos. Resolución WHA51.17, 1998, punto 21.3 del orden del día.

9. Fleming-Dutra KE, Hersh AL, Shapiro DJ, Bartoce M, Enns EA, File TM Jr, et al. Prevalence of Inappropriate Antibiotic Prescriptions Among US Ambulatory Care Visits, 2010-2011. JAMA. 2016; 315(17):1864-1873. doi:10.1001/jama.2016.4151

10. La AEMPS considera inadecuadas el 40-50\% de las prescripciones de antibióticos en AP y en hospitales. Jano.es. Medicina y Humanidades. 15 de noviembre de 2015 (en línea). [Consultado 25/04/2016]. Disponible en: http://www.jano.es/noti- cia-la-aemps-considera-inadecuadas-el-25166

11. Antimicrobial resistance and causes of non-prudent use of antibiotics in human medicine (ARNA Project). [Internet] The Netherlands; 2016. [Consultado 25/04/2016]. Disponible en: https://www.nivel.nl/en/arna

12. Special Eurobarometer 407: Antimicrobial Resistence. Survey requested by the European Commission, Directorate-General for Health and Food Safety and co-ordinated by the Directorate-General for Communication. [Internet] European Union; 2013. [Consultado 25/04/2016]. Disponible en: http://ec.europa.eu/health/antimicrobial_resistance/docs/ebs_407_en.pdf

13. Special Eurobarometer 445: Antimicrobial Resistence. Survey requested by the European Commission, Directorate-General for Health and Food Safety and co-ordinated by the Directorate-General for Communication. European Union; 2016. [Consultado 29/08/2016]. Disponible en: http://ec.europa.eu/COMMFrontOffice/PublicOpinion/index.cfm/Survey/ getSurveyDetail/search/Antimicrobial\%20Resistance/surveyKy/21070

14. SEFAC. 15 Retos para el presente y el futuro de la farmacia comunitaria. Barcelona: Sefac; 2016.

15. El papel del farmacéutico en el autocuidado y la automedicación. Reporte de la 4a Reunión del Grupo Consultivo de la OMS sobre el papel del farmacéutico. La Haya: OMS; 1998. [Consultado 29/04/2016]. Disponible en: http://mayoristabebe.com.ar/safyb. org.ar/archivos/OMSAutocuidado.pdf

16. The role of the pharmacist in the health care system. Preparing the future pharmacist: Curricular development. Report of a third WHO Consultative Group on the role of the pharmacist, Vancouver, Canada, 27-29 August 1997. [Internet]. Geneva: World Health Organization; 1997. WHO/PHARM/97/599. Disponible en: http://www.who.int/medicinedocs/

17. Real Decreto $1718 / 2010$, de 17 de diciembre, sobre receta médica y órdenes de dispensación. Boletín Oficial del Estado, no 17, (20-01-2011).

18. Salar Ibáñez L. Estudio de la demanda de antibióticos sin receta en la oficina de farmacia. [Tesis doctoral]. Valencia: Universidad CEU Cardenal Herrera; 2006.

19. Foro de Atención Farmacéutica. Documento de Consenso. Panorama Actual del Medicamento 2014; 38(375): 645-676.

20. Agencia Española de Medicamentos y Productos Sanitarios (AEMPS). Plan estratégico y de acción para reducir el riesgo de selección y diseminación de la resistencia a los antibióticos. Madrid: AEMPS; 2015.
21. Fernández Lorenzo MJ, Fornos Pérez JA, García Sánchez AM, Guerra García MM, Novoa Romero I, Alén de la Torre MT, et al. Peticiones de antibióticos en las farmacias comunitarias. BIM-FARMA 2002; 40:1-5.

22. Llull R, Moranta F, Oliver T. Demanda de antibióticos sin receta en las Illes Balears. Farmacéuticos Comunitarios 2010; 2(suplemento 1).

23. Salar Ibañez, L, Eyaralar Riera MT, Baixauli Fernández VJ, Fité Novellas B, García Cebrián F, Gérvas Camacho J. Demanda de antibióticos sin receta en farmacia comunitaria. Pharmaceutical Care España 2006; 8(4):147-197.

24. Zapata-Cachafeiro M, González-González C, Vázquez-Lago P, López-Durán A, Smyth E, Figueiras A. Determinants of antibiotic dispensing without a medical prescription: a cross-sectional study in the north of Spain. J Antimicrob Chemother 2014; 69: 3156-60. https://doi.org/10.1093/jac/dku229

25. Plan Nacional Resistencia Antibióticos. Consumo de antibióticos de uso sistémico (J01) en Atención Primaria. [Internet]. Madrid: PRAN; 2017. [Consultado 10-03-2018]. Disponible en: http://www.resistenciaantibioticos.es/es/profesionales/vigilancia/ mapas-de-consumo/consumos-antibioticos-en-atencion-primaria

26. Gastelurrutia MA, Larrañaga B, Ortega $\mathrm{B}$, Puntonet L. Evaluación del programa de uso racional de antibióticos en Guipúzcoa. Primera fase 19992000. Pharmaceutical Care España 2002; 4(3):143-157.

27. Consejo General de Colegios Oficiales de Farmacéuticos. Estadísticas de colegiados y farmacias comunitarias 2017. [Internet]. Farmacéuticos 2017; 426:17. [Acceso 20-02-2018]. Disponible en: http://www.portalfarma. com/Profesionales/infoestadistica/Documents/Documentos-acceso-medios/ Estad\%C3\%ADsticas-Colegiados-Farmacias-Comunitarias-2016.pdf

28. Sociedad Española de Farmacia Familiar y Comunitaria. Memoria anual 2016. Barcelona: Edittec: 2017.

29. Salar L, Prats R, Eyaralar T, Espejo J. Programa 'I-Valor': la indicación farmacéutica protocolizada, consensuada y registrada en la farmacia comunitaria. Farmacéuticos Comunitarios. 2017 Sep 30; 9(3):5-12. doi:10.5672/ FC.2173-9218.(2017/Vol9).003.02

30. Martín A, Cervero M, Molinero A, Magro MC, Mateos AM, Partearroyo T. Estudio MePAFac nacional: medida de presión arterial (PA) y educación sanitaria en factores de riesgo cardiovascular en centros escolares desde la farmacia comunitaria. Resultados preliminares nacionales. Farmacéuticos Comunitarios. 2016 May 26; 8(Suplemento 1). 